\title{
The Unusual Response of Serotonergic Neurons after CNS Injury: Lack of Axonal Dieback and Enhanced Sprouting within the Inhibitory Environment of the Glial Scar
}

\author{
Alicia L. Hawthorne, ${ }^{1}$ Hongmei Hu, ${ }^{1}$ Bornali Kundu, ${ }^{1}$ Michael P. Steinmetz, ${ }^{2}$ Christi J. Wylie, ${ }^{1}$ Evan S. Deneris, ${ }^{1}$ \\ and Jerry Silver ${ }^{1}$ \\ ${ }^{1}$ Department of Neurosciences, Case Western Reserve University, Cleveland, Ohio 44106, and 2Department of Neurosurgery, Cleveland Clinic Foundation, \\ Cleveland, Ohio 44195
}

\begin{abstract}
Serotonergic neurons possess an enhanced ability to regenerate or sprout after many types of injury. To understand the mechanisms that underlie their unusual properties, we used a combinatorial approach comparing the behavior of serotonergic and cortical axon tips over time in the same injury environment in vivo and to growth-promoting or growth-inhibitory substrates in vitro. After a thermocoagulatory lesion in the rat frontoparietal cortex, callosal axons become dystrophic and die back. Serotonergic axons, however, persist within the lesion edge. At the third week post-injury, 5-HT+ axons sprout robustly. The lesion environment contains both growth-inhibitory chondroitin sulfate proteoglycans (CSPGs) and growth-promoting laminin. Transgenic mouse serotonergic neurons specifically labeled by enhanced yellow fluorescent protein under control of the Pet-1 promoter/enhancer or cortical neurons were cultured on low amounts of laminin with or without relatively high concentrations of the CSPG aggrecan. Serotonergic neurons extended considerably longer neurites than did cortical neurons on low laminin and exhibited a remarkably more active growth cone on low laminin plus aggrecan during time-lapse imaging than did cortical neurons. Chondroitinase $A B C$ treatment of laminin/CSPG substrates resulted in significantly longer serotonergic but not cortical neurite lengths. This increased ability of serotonergic neurons to robustly grow on high amounts of CSPG may be partially due to significantly higher amounts of growth-associated protein- 43 and/or $\beta 1$ integrin than cortical neurons. Blocking $\beta 1$ integrin decreased serotonergic and cortical outgrowth on laminin. Determining the mechanism by which serotonergic fibers persist and sprout after lesion could lead to therapeutic strategies for both stroke and spinal cord injury.
\end{abstract}

\section{Introduction}

After injury to the CNS, reactive astrocytes hypertrophy over time, forming a physical barrier, but they also secrete a variety of inhibitory chondroitin/keratan sulfate proteoglycans, forming a more immediate molecular barrier that contributes to a longterm dystrophic state in the vast majority of nonregenerating fibers (Silver and Miller, 2004; Busch and Silver, 2007; Schachtrup et al., 2007; Fitch and Silver, 2008). Dystrophic axons, which exhibit a variety of unusual morphologies (Ramon y Cajal, 1928; Tom et al., 2004), lack filopodia, are bulbous, sometimes vacuolated, and tend to move backwards over time. Macrophages enter the lesion to clear debris, but they also participate in the long-distance dieback of dystrophic axons (Horn et al., 2008; Busch et al., 2009; Gensel et al., 2009; Kigerl et al., 2009).

Although serotonergic neuronal cell bodies are located in the midbrain/hindbrain raphe, their fibers project throughout the

\footnotetext{
Received Dec. 21, 2010; accepted Feb. 7, 2011.

This work was supported by National Institutes of Health (NIH)-National Institute of Neurological Disorders and Stroke Grant NS25713 (J.S.) and NIH Grant R01MH62723 (E.S.D.). We thank Maryanne Pendergast and Cathy Doller for their technical assistance. We thank Heather Broihier for the generous use of equipment.

Correspondence should be addressed to Jerry Silver, Department of Neurosciences, Case Western Reserve University, 10900 Euclid Avenue, Cleveland, 0H 44106. E-mail: jxs10@cwru.edu.

DOI:10.1523/JNEUROSCI.6663-10.2011

Copyright $\odot 2011$ the authors $\quad 0270-6474 / 11 / 315605-12 \$ 15.00 / 0$
}

CNS and even into regions, such as the subventricular zone, that tend to be refractory to the entrance of other axons (Levitt and Moore, 1978; Lorez and Richards, 1982; Wallace and Lauder, 1983; Azmitia and Whitaker-Azmitia, 1991). These neurons have the added tendency to sprout after injury, whether caused by direct chemical lesion (Zhou et al., 1995) or spinal cord trauma (Sharma et al., 1990; Inman and Steward, 2003; Camand et al., 2004). When transplanted into the injured adult spinal cord, serotonergic neurons can elongate and incorporate remarkably well into the CNS parenchyma (Privat et al., 1986; Foster et al., 1989; Yakovleff et al., 1995; Feraboli-Lohnherr et al., 1997; Ribotta et al., 2000), where they can bring about a measure of functional recovery. Clearly, there must be some as yet unknown special property within these neurons that allows them to survive so well within inhibitory environments.

We have begun to examine the mechanisms by which serotonergic neurons overcome the deleterious effects of CNS trauma by closely comparing their responses to injury with another system of projection neurons in the same hostile lesion environment. We chose a focal, superficial thermocoagulatory lesion of the frontoparietal cortex (Szele et al., 1995) that simultaneously axotomizes both callosal and serotonergic fibers within the same expanse of cortical gray matter. The time course of their behaviors after lesion revealed that callosal fibers become dystrophic and rapidly die back into the white matter, whereas serotonergic 
fibers persist at the penumbra of the lesion and sprout within regions containing many inflammatory cells, laminin and high levels of chondroitin sulfate proteoglycan (CSPG). We then compared cortical and specifically marked enhanced yellow fluorescent protein under control of the Pet-1 promoter/enhancer (ePet-EYFP) serotonergic neurons in vitro using time-lapse imaging and immunofluorescence. Serotonergic neurons maintain a more active growth cone when challenged with CSPG-rich substrates and achieve longer neurite lengths after chondroitinase $\mathrm{ABC}(\mathrm{ChABC})$ treatment. These differences may be partially attributable to higher levels of growth-associated protein-43 (GAP43 ) and/or $\beta 1$ integrin, part of the receptor complex for laminin (Milner and Campbell, 2002), in serotonergic versus cortical neurons. Discerning the unique navigational characteristics of serotonergic neurons may aid in devising strategies to instill their positive intrinsic attributes into other types of neurons that fare less well following injury.

\section{Materials and Methods}

\section{Thermocoagulatory lesion}

Adult female Sprague Dawley rats (200-300 g) were anesthetized by ketamine $(100 \mathrm{mg} / \mathrm{kg}$; Fort Dodge Animal Health) and xylazine (2.4 $\mathrm{mg} / \mathrm{kg}$; Lloyd Laboratories) intramuscular injection. The thermocoagulatory lesion was administered as described previously (Szele et al., 1995). Briefly, a unilateral left craniectomy was performed from anteroposterior (AP) $+2.0 \mathrm{~mm}$ to $-8.0 \mathrm{~mm}$ from bregma, mediolateral (ML) just lateral to the midline and extending to the temporal bone. The lesion was caused by cauterizing the meningeal blood vessels with rapid, light touches by a hot probe. After cauterization was complete, the area was covered with Gelfilm (Pfizer) and the incision was stapled. Sham animals were treated the same but without cauterization. Marcaine $(1.0 \mathrm{mg} / \mathrm{kg}$; Hospira) was applied subcutaneously along the incision site. Animals were given buprenorphine $(0.1 \mathrm{mg} / \mathrm{kg}$; Reckitt Benckiser Pharmaceuticals) intramuscularly every $12 \mathrm{~h}$ for $24 \mathrm{~h}$. Six animals were used per sham or experimental group, for a total of 60 animals. Animals were perfused $2 \mathrm{~d}$, $4 \mathrm{~d}, 1$ week, 3 weeks, or 5 weeks after lesion.

\section{Anterograde tracing}

Callosal neurons were anterogradely labeled 1 week before perfusion. Biotinylated dextran amine (BDA) (10\% in 0.05 м PBS; 10,000 molecular weight; Invitrogen) was injected into layer $V$ of the contralateral cortex $(+1.2$ $\mathrm{mm}$ AP from bregma, $-3.0 \mathrm{~mm}$ ML from bregma, $-2.1 \mathrm{~mm}$ dorsoventral from the surface of the brain) with a Nanoject II (Drummond Scientific Co.), 28 injections of $23 \mathrm{nl}$ every $15 \mathrm{~s}$, for a total of $0.644 \mu \mathrm{l}$.

\section{In vitro neuronal culture}

ePet-EYFP mice were bred in a mixed C57BL/6 and 129 background (Hendricks et al., 1999; Scott et al., 2005a,b; Hawthorne et al., 2010). The age postnatal day 3 (P3)-P4 was chosen because the yield of serotonergic neurons in culture decreased as the age increased (maximum age tried was P20). Pups were overexposed to isoflurane and beheaded. The dissection was a modified version of Brewer and Torricelli (2007) with the following changes. After dissection, brains were genotyped as EYFP+ using a fluorescence dissecting microscope in low fluorescence Hibernate-A (BrainBits LLC) plus B27 (Invitrogen) plus GlutaMAX (Invitrogen). The $\mathrm{EYFP}+$ raphe was dissected out using the fluorescence dissecting microscope for the serotonergic culture. The cortex was dissected from EYFPbrains for the cortical culture. Dissected tissue was cut into small pieces with a razor blade, and a nonsiliconized Pasteur pipette was used. Neurons were plated in glass-bottom Delta T dishes (Fisher Scientific) coated with poly-L-lysine $(0.1 \mathrm{mg} / \mathrm{ml}$; Sigma $)$ overnight at room temperature with or without $1 \mu \mathrm{g} / \mathrm{ml}$ laminin (Invitrogen) $\pm 100 \mu \mathrm{g} / \mathrm{ml}$ aggrecan (Sigma) for at least $2 \mathrm{~h}$ at $37^{\circ} \mathrm{C}$ at the following densities: 400,000 cells/ dish for serotonergic neurons on laminin, 550,000 cells/dish for serotonergic neurons on poly-L-lysine (PLL) alone or aggrecan, 700,000 cells/ dish for cortical neurons. Cortical neurons needed higher densities to grow well. Serotonergic neurons grew so well on laminin that the density had to be decreased. The medium was Neurobasal-A (Invitrogen) plus B27, penicillin-streptomycin (Invitrogen), GlutaMAX, and 5-fluoro-2'-deoxyuridine (FUDR) ( $5 \mu \mathrm{m}$; Sigma) to prevent glial division.

\section{Time-lapse imaging}

After 2 days in vitro (DIV), the medium was changed to Neurobasal-A plus B27, penicillin-streptomycin, GlutaMAX, and HEPES (50 $\mu \mathrm{M}$; Sigma), each dish was covered with a coverglass, and neurons were imaged via time-lapse (MetaMorph 6.2r6, MDS Analytical Technologies) with a heated stage and a heated $100 \times$ objective. EYFP + neurons were located by fluorescence, and a fluorescence image was taken. Bright-field images were taken every $30 \mathrm{~s}$ and compiled into a movie (see Notes).

\section{ChABC treatment}

After 1 DIV, medium was replaced with new medium containing ChABC (0.5 U; Associates of Cape Cod) or saline. Cells were fixed after 1 more DIV, for 2 DIV total.

\section{$\beta 1$ integrin treatment}

At the time of plating on $1 \mu \mathrm{g} / \mathrm{ml}$ laminin, $50 \mu \mathrm{g} / \mathrm{ml}(100 \mu \mathrm{g}$ total) of either function-blocking anti- $\beta 1$ integrin (hamster anti-CD29, clone $\mathrm{Ha} 2 / 5$; BD Biosciences) or isotype control (hamster anti-IgM, clone G235-1; BD PharMingen) was added to the culture medium. Cells were fixed after 1 DIV.

\section{Immunofluorescence}

Animals were overexposed to isoflurane (AERRANE; Baxter) and transcardially perfused with cold $4 \%$ paraformaldehyde (PFA) (Fisher Scientific) in PBS (Roche). Brains were dissected out, postfixed overnight in $4 \%$ PFA, and cryoprotected with 30\% sucrose (Fisher Scientific) $1-2 \mathrm{~d}$ until the tissue sank. Tissue was frozen in Frozen Section Medium (Fisher Scientific) and cryosectioned into $20 \mu \mathrm{m}$ coronal sections. Sections were dried onto Superfrost Plus slides (Fisher Scientific). Cells were fixed with cold $4 \%$ PFA. Tissue and cells were blocked overnight at $4^{\circ} \mathrm{C}$ in $5 \%$ normal goat serum (Invitrogen) or donkey serum (Millipore Bioscience Research Reagents), $0.1 \%$ bovine serum albumin (Sigma), with or without $0.1 \%$ Triton-X (Sigma) to permeabilize cells, in PBS. Primary antibodies were applied in blocking solution overnight at $4^{\circ} \mathrm{C}$. Primary antibodies were to chondroitin sulfate proteoglycan (CS-56; mouse IgM; 1:500; Sigma), laminin (rabbit; 1:500; Biomedical Technologies), 5-HT (serotonin; rabbit; 1:10,000; Immunostar), SERT (serotonin transporter) (rabbit; 1:500-800; Immunostar; or mouse $\operatorname{IgG}_{1} ; 1: 500-1000$; Millipore Bioscience Research Reagents), vimentin (clone LN-6; mouse IgM; 1:200; Sigma), glial fibrillary acidic protein (GFAP) (clone G-A-5; mouse IgG $\mathrm{Ig}_{1}$ 1:500; Sigma), blood vessel marker RECA-1 (mouse IgG 1:500; Serotec), macrophage/microglial marker ED1 (mouse IgG ${ }_{1} ; 1: 500$; Millipore Bioscience Research Reagents), $\beta$-tubulin III (mouse $\operatorname{IgG}_{2 \mathrm{~b}}$; 1:500; Sigma), GAP-43 (goat IgG; 1:4000; a kind gift from Dr. Larry Benowitz, Children's Hospital/Harvard Medical School, Boston, MA), integrin $\alpha 1$ (F-19), $\alpha 2$ (N-19), $\alpha 3$ (N-19), $\alpha 6$ (N-19) (goat IgG; 1:50; Santa Cruz Biotechnology), integrin $\beta 1$ (Rat $\operatorname{IgG}_{2 \mathrm{k}}, 1: 50$; Millipore). Yellow fluorescent protein was recognized with an antibody to green fluorescent protein (rabbit; 1:500; Invitrogen).

After washing 3 times in PBS, slides and cells were incubated with blocking solution containing the appropriate secondary antibody raised in goat (Alexa Fluor 350, 488, 594 or 647; 1:500; Invitrogen) or donkey (anti-goat biotin; 1:500; Jackson ImmunoResearch Laboratories) overnight at $4^{\circ} \mathrm{C}$ or $2 \mathrm{~h}$ at room temperature. BDA was visualized by Streptavidin Alexa 488 or 594 (1:500; Invitrogen) using the same protocol as for secondary antibodies. Then, slides and cells were washed 3 times in PBS. DNA was visualized with DAPI ( $1 \mu \mathrm{g} / \mathrm{ml}$; Sigma) for $10 \mathrm{~min}$ at room temperature in PBS. Slides were coverslipped using 1:1 PBS/ Citifluor (Ted Pella) mounting medium. Tissue images were collapsed $Z$-stacks in the coronal plane obtained from a Zeiss LSM 510 confocal microscope.

\section{Quantification}

Fiber distance from corpus callosum. The distance from the corpus callosum to the most dorsal serotonergic or BDA-labeled cortical fiber was measured in 3 animals per condition, 3 sections per animal using MetaMorph (MDS Analytical Technologies). 

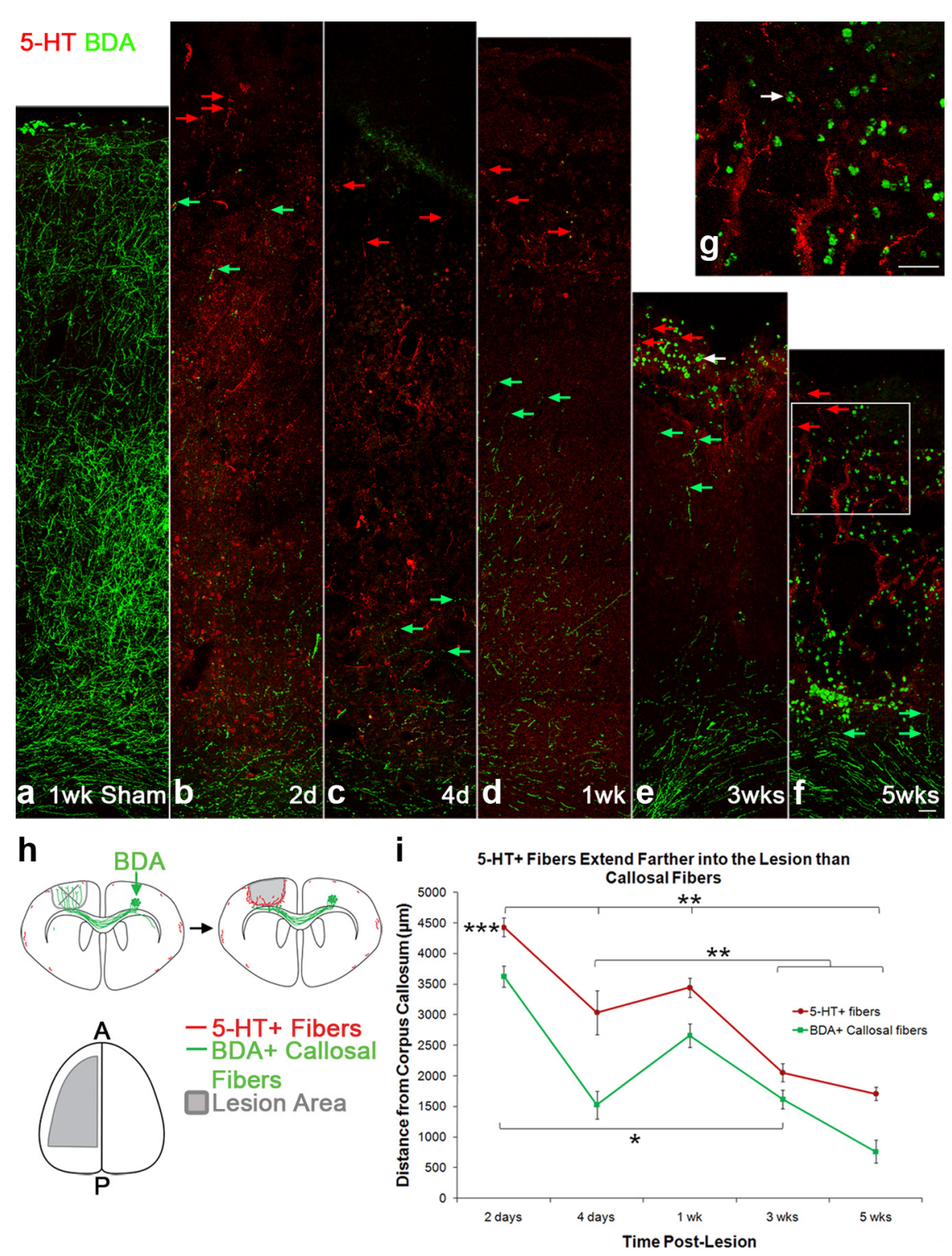

Figure 1. Serotonergic fibers persist at the lesion edge, while callosal fibers die back. $\boldsymbol{a}$, BDA-labeled callosal fibers (green) project to the pial surface in sham animals without a lesion. $\boldsymbol{b}$, Two days after lesion the majority of BDA-labeled fibers retracted toward the corpus callosum, with a few fibers extending more dorsally. 5 -HT-labeled serotonergic fibers (red) remain near the pial surface. The three most dorsally projecting 5-HT+ (red) and BDA + (green) fibers are marked with arrows. $\boldsymbol{c}, \boldsymbol{d}, \mathrm{At} 4 \mathrm{~d}(\boldsymbol{c})$ and 1 week (d) after lesion, the cavity has not receded and 5-HT + fibers remain dorsal, while BDA + fibers continue to regress toward the corpus callosum. The white arrow marks a BDA + macrophage. $\boldsymbol{e}, \boldsymbol{f}$, At 3 weeks $(\boldsymbol{e})$ and 5 weeks $(\boldsymbol{f})$ after injury, the lesion has receded, forming a cavity. $\boldsymbol{g}, 5$-HT + fibers are present at the edge of the cavity, growing among BDA-filled macrophages and holes in the tissue. BDA + fibers are mostly present in the corpus callosum, with few extending dorsally. $\boldsymbol{h}, A$ schematic of the lesion (gray) in coronal section (top) and dorsal view (bottom). $i$, Quantification of the farthest dorsal extent of 5 -HT + and BDA + fibers. 5 -HT + fibers extend significantly farther into the lesion than callosal fibers (two-way ANOVA, $F_{(1,80)}=51.58$, Tukey posthoc test). All time-points are significant from each other except for 1 week from 3 weeks and 3 weeks from 5 weeks (two-way ANOVA $F_{(4,80)}=60.77$, Tukey post hoc test). Mean \pm SEM is displayed. ${ }^{* * *} p<0.0001,{ }^{* *} p<0.001,{ }^{*} p<0.002$. Scale bar, $50 \mu \mathrm{m}$.

Serotonergic fiber area. An image was taken from the same location in each animal, 5-9 animals per time-point. The area of 5-HT+ fibers was thresholded using MetaMorph (MDS Analytical Technologies).

Time-lapse classification. The behavior of the neuron in each timelapse movie was categorized and graphed (see Notes).

Neurite length. Images of neurons were taken with a Zeiss Axiovert $200 \mathrm{M}$ fluorescence microscope using Axiovision. The length of the longest neurite from cortical and serotonergic neurons was measured using NIH ImageJ (W. Rasband, National Institutes of Health, Bethesda, MD). If no neurites were seen from a cluster of cell bodies, each clearly discernable cell body was given the score of 0 . If neurites were present from a cluster of cell bodies, only the longest neurite was recorded. Three inde- pendent experiments were analyzed. Two independent experiments were analyzed for anti- $\beta 1$ integrin measurements.

GAP-43 and $\beta 1$ integrin fluorescence intensity. Images were taken with a Zeiss Axiovert 200M fluorescence microscope using Axiovision. Cortical neurons were double stained with $\beta$-tubulin III, and serotonergic neurons were double stained with 5-HT. Exposure times were kept constant for each immunostain. Fluorescence intensity and the area of the cell body were measured using MetaMorph (MDS Analytical Technologies). Three independent experiments were analyzed.

\section{Statistical analysis}

To analyze the fiber distance from the corpus callosum, a two-way ANOVA and Tukey post hoc test were performed using Minitab 15 (Minitab Inc.). Neurite lengths were compared by the Mann-Whitney Utest, the nonparametric equivalent to the two-sample $t$ test, using Minitab. The 5 -HT + fiber area and the ChABC experiment were analyzed by the Kruskal-Wallis test, the nonparametric equivalent to ANOVA, and Mann-Whitney $U$ test for post hoc measures using SPSS Statistics 17.0.

\section{Results}

Serotonergic fibers persist at the edge of the lesion

We studied the behavior of two types of projection axons, cortical callosal fibers and serotonergic fibers, over time after injury. A superficial thermocoagulatory lesion in the rat frontoparietal cortex (Szele et al., 1995) causes a focal infarct deeper within the cortex (Fig. $1 h$ ) due to cauterization of the pial blood vessels and ensuing ischemia. The resulting injury, which extends toward but does not include the corpus callosum, was analyzed at $2 \mathrm{~d}, 4 \mathrm{~d}$, 1 week, 3 weeks, or 5 weeks after lesion. Callosal fibers were labeled by anterograde tracing via contralateral injection of BDA into layer $\mathrm{V}$ cell bodies in the cortex contralateral and homotopic to the lesion. Serotonergic fibers were labeled by $5-\mathrm{HT}$ immunostaining. A sham surgery in which a craniectomy was performed without cauterization showed that BDA + fibers, which normally project from the corpus callosum profusely with some fibers reaching the pial surface (Akers and Killackey, 1978; Koralek et al., 1990; Nicolelis et al., 1991), were undisturbed in control conditions (Fig. 1a). The 5-HT antibody labels fibers diffusely throughout the cortex (Fig. 1a), but the serotonin transporter antibody SERT labels more of the fibers that distribute throughout the cortex. The 5-HT antibody, however, has much higher fidelity and does label all of the fibers labeled by SERT near the lesion. Already at $2 \mathrm{~d}$ after lesion, BDA + callosal fibers had begun to die back toward the body of the corpus callosum (Fig. 1b). A smaller number of fibers extended dorsally. Conversely, 5-HT + fibers were detected much nearer the pial surface. As tissue death proceeded 

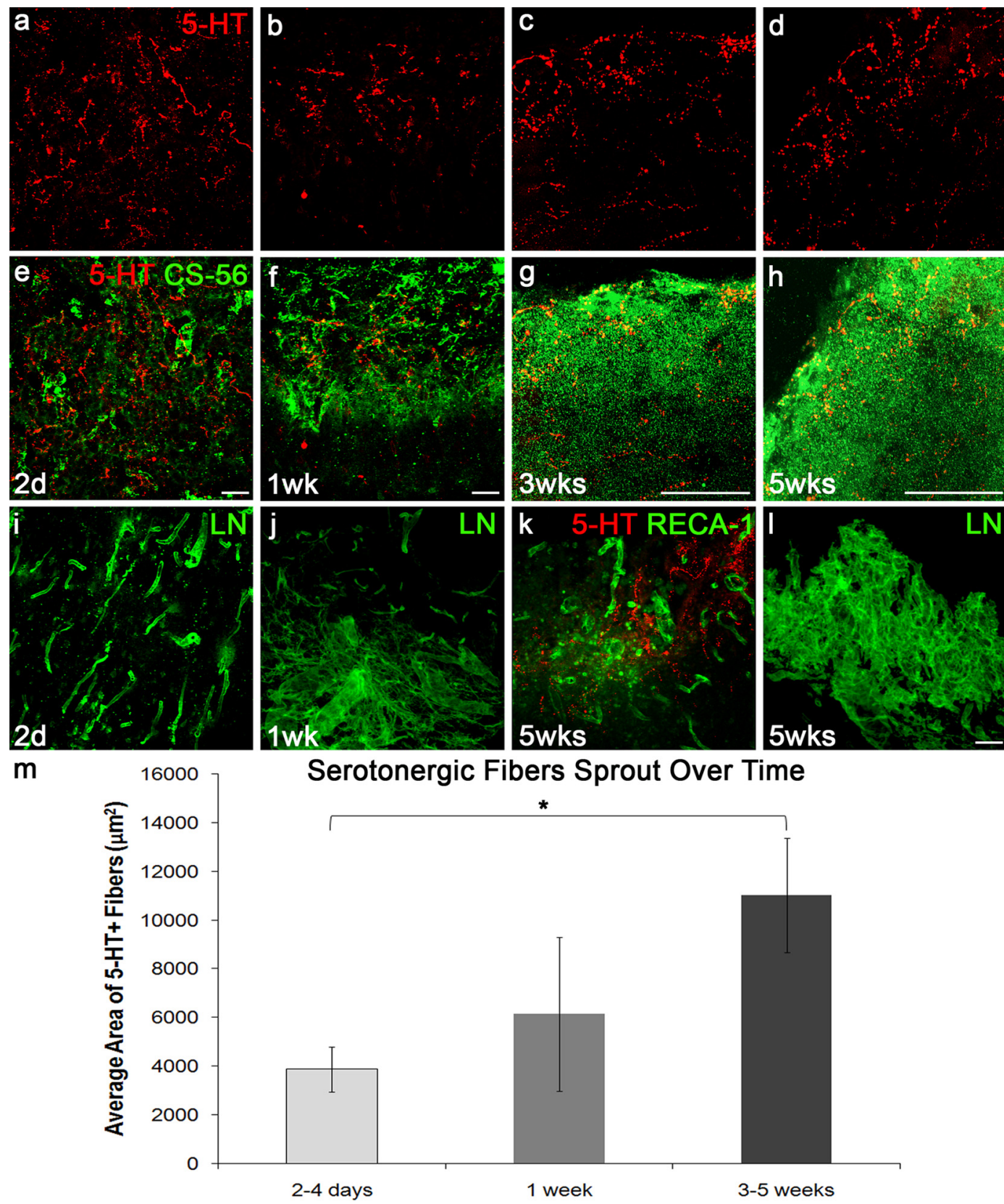

nergic Fibers Sprout Over Time

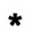




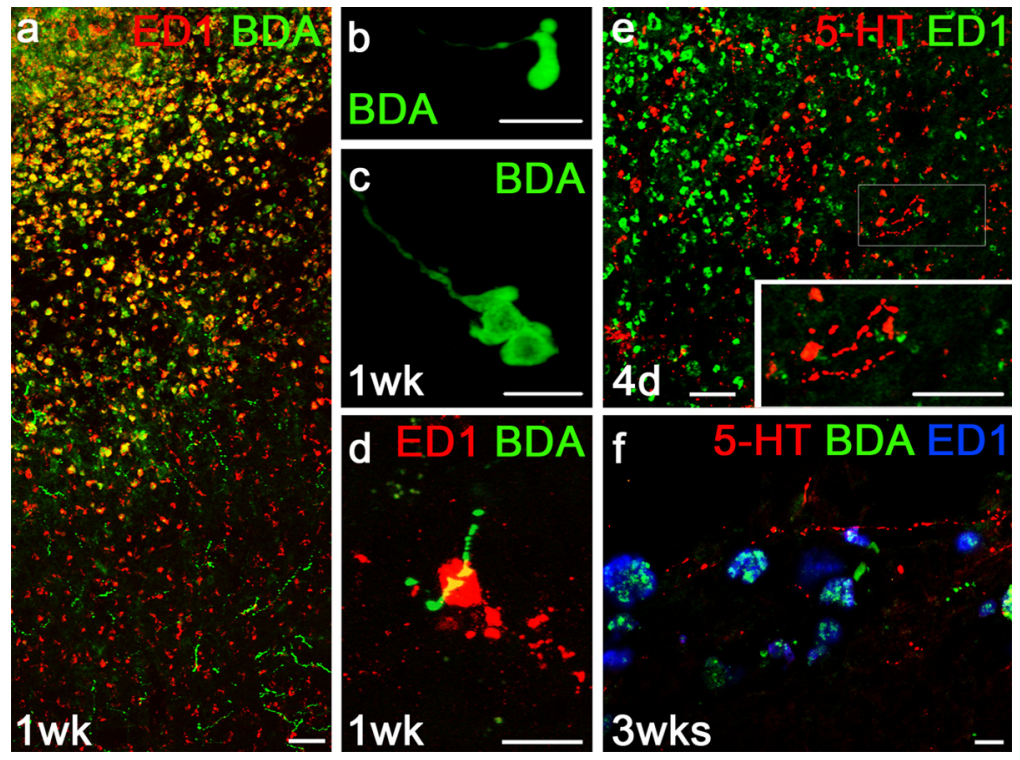

Figure 3. Callosal fibers die back away from macrophages/microglia, while serotonergic fibers grow among them. $\boldsymbol{a}$, Many macrophages/microglia labeled by ED1 (red) are also positive for BDA (green). $\boldsymbol{b}, \boldsymbol{c}, \mathrm{BDA}+$ ending can be bulbous and dystrophic in morphology. $\boldsymbol{d}, \mathrm{ED} 1+$ macrophage/microglia can engulf BDA + fibers. $\boldsymbol{e}, 5-\mathrm{HT}+$ fibers (red) are present among the ED1+ macrophages/microglia (green). The inset shows a magnified view of serotonergic fibers, which have beads that are much smaller than the dystrophic endings of BDA + fibers.f, Macrophages/microglia (blue) are filled with BDA (green) but not 5-HT (red). Scale bars: $\boldsymbol{a}, \boldsymbol{e}, 50 \mu \mathrm{m} ; \boldsymbol{b}-\boldsymbol{e}$, inset, $\boldsymbol{f}, 10 \mu \mathrm{m}$
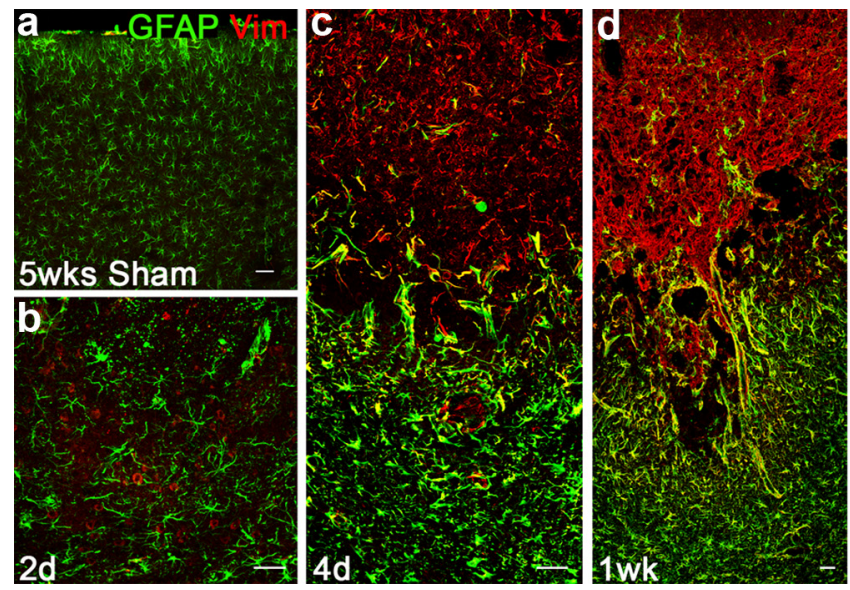

Figure 4. Vimentin + cells are present dorsally in the lesion, while GFAP + cells are present ventrally. $\boldsymbol{a}$, Sham animals do not have hypertrophic GFAP + astrocytes (green) or vimentin + cells (red) in the cortex. $\boldsymbol{b}$, Two days after lesion, GFAP + cells begin to increase in size, and there is low vimentin staining. c, Four days after lesion, vimentin + cells are increased dorsally, while GFAP staining increases ventrally. $\boldsymbol{d}$, One week after lesion, vimentin + and GFAP + cells continue to increase, with a region of overlap (yellow).e, $\boldsymbol{f}$, After cavity formation, vimentin + cells are present dorsally, GFAP + cells are present ventrally, and a strong area of overlap exists where they meet. $\boldsymbol{f}$, At higher magnification, colabeled and single-labeled cells are clearly seen. Scale bars, $50 \mu \mathrm{m}$.

\section{Serotonergic fibers sprout within high levels of chondroitin sulfate proteoglycan and laminin}

We next characterized the lesion environment for inhibitory and growth-promoting extracellular matrix (ECM) proteins. CSPGs are ECM molecules found in the glial scar that are inhibitory to the growth and regeneration of axons (Silver and Miller, 2004; Busch and Silver, 2007; Fitch and Silver, 2008). CSPGs, identified by the antibody CS-56, were already present $2 \mathrm{~d}$ postlesion, especially within the lesion penumbra (Fig. 2e). At this time, 5-HT+ fibers were evenly spread within this territory (Fig. $2 a, e$ ). However, $\mathrm{BDA}+$ fibers retracted away from this region nearer to the corpus callosum. By 1 week after lesion, 5-HT+ fibers were enriched at the border between healthy and damaged tissue among

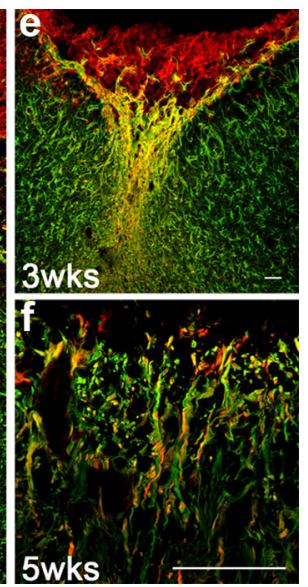

the higher levels of CS-56 staining (Fig. $2 b, f)$. At 3 and 5 weeks after lesion, CS-56 immunostaining remained highest at the lesion edge and tapered ventrally in a decreasing gradient (Fig. $2 g, h$ ). Surprisingly, $5-\mathrm{HT}+$ fibers were not only present among the high levels of CSPG at the lesion edge, but they also increased in density in the same location (Fig. $2 c, d, g, h$ ). Note that in Figure 2,c and $d$ are at a higher magnification (more than double) than $a$ and $b$, which emphasizes the "pearls on a string" or beaded appearance of serotonergic fibers. This increased density, compared with $2 \mathrm{~d}$ after lesion, suggested that $5-\mathrm{HT}+$ fibers had sprouted. Indeed, when the tissue containing 5-HT+ fibers was quantified, significantly more area was occupied by $5-\mathrm{HT}+$ fibers at $3-5$ weeks after lesion compared with 2-4 d after lesion (Kruskal-Wallis $\chi^{2}(2)=$ 8.650, Mann-Whitney U post hoc test, $p<$ $0.005)$. Coincident with the increase in CSPG was an increase in potentially growth-promoting laminin. Two days after injury, laminin was found in the vicinity of blood vessels but also scattered throughout the penumbra (Fig. 2i). The amount of laminin staining increased at 1 week (Fig. 2j) and continued to increase through 5 weeks after lesion, especially in the lesion center (Fig. $2 l$ ). The majority of the laminin was not associated with RECA-1 immunostaining for blood vessels, some of which appeared highly fragmented (Fig. 2k). 5-HT+ fibers were present in high density within the regions enriched in laminin but, at this stage, were not closely associated with blood vessels (Fig. $2 k$ ). Thus, the lesion edge becomes enriched in CSPG and laminin, and in this environment 5 -HT + fibers sprout but $\mathrm{BDA}+$ callosal fibers retract.

\section{Serotonergic fibers survive among} macrophages/microglia, GFAP+ and vimentin + cells, while callosal fibers die back

Macrophages/microglia are not only part of the inflammatory response to CNS injury but also can cause dystrophic growth cones to retract (Horn et al., 2008; Busch et al., 2009). Macrophages/microglia were present in large numbers beginning $4 \mathrm{~d}$ after lesion (Fig. $3 e$ ), and persisting through 5 weeks (Figs. 3a). By 1 week after lesion macrophages/microglia colabeled for both the macrophage/microglia marker ED1 but also BDA. Many BDA+ callosal axons had enlarged, containing bulbous endings characteristic of failed regeneration (Fig. $3 b, c$ ). The ED1 and BDA colabeling (Fig. 3a,d,f) suggests that the macrophages/microglia may take up BDA from the environment or phagocytose the degenerating $\mathrm{BDA}+$ fibers themselves. Conversely and importantly, no ED1+ macrophages/microglia were observed to colabel with 5-HT or engulf 5 -HT + fibers (Fig. 3e,f). No enlarged endings were detected in 
5-HT + fibers, which were present in close proximity to the potentially inhibitory/ destructive macrophages/microglia (Fig. $3 e, f)$. After tissue cavitation, the number of macrophages/microglia decreased, but those that remained were strongly BDA+ (Figs. $1 e-g, 3 f$ ). Thus, dystrophic $\mathrm{BDA}+$ fibers retract from the region of macrophages/microglia, which may aid in dieback, while 5 -HT + fibers sprout in the same region.

After injury, GFAP+ astrocytes hypertrophy and form the inhibitory glial scar (Silver and Miller, 2004; Busch and Silver, 2007; Fitch and Silver, 2008). Vimentin+ cells also appear within CNS lesions and can represent immature or mature astrocytes (Yang et al., 1994), oligodendrocyte progenitor cells (Horky et al., 2006; Busch et al., 2010), endothelial cells (Fujimoto and Singer, 1986), fibroblasts (Holwell et al., 1997), or macrophages/microglia (Correia et al., 1999). In sham-treated animals, weakly stained GFAP + astrocytes were present throughout the cortex but not vimentin + cells (Fig. 4a). At $2 \mathrm{~d}$ after lesion, GFAP staining intensified in the vicinity of the lesion but very few vimentin + cells were detected (Fig. 4b). Immunostaining for both GFAP and vimentin increased over time (Fig. $4 c-f$ ). At $4 \mathrm{~d}$ and 1 week after lesion, vimentin + cells extended ventrally from the pial surface toward and into the tissue mass that would eventually cavitate (Fig. $4 c, d$ ). GFAP + cells were at their highest density in the border between injured and healthy tissue, where CSPG was also highest (Fig. 2f). Where the two cell types met there was an area of colabeled GFAP+/vimentin + astrocytes (Fig. $4 c-f$ ). After 3 and 5 weeks, as the tissue cavity receded, GFAP +/vimentin + cells formed a clear border at the lesion edge (Fig. 4e,f). Only GFAP + reactive astrocytes continued ventrally toward the callosum. A high-magnification image shows single- and doublelabeled cells in the lesion border (Fig. $4 f$ ). BDA+ fibers were mostly present in the area of GFAP + cells nearer the callosum, while $5-\mathrm{HT}+$ fibers extended much further peripherally into the region of vimentin + cells at the lesion edge (Figs. 1, 4). The increase in GFAP + cells mirrors the increase in CSPG, and the onset of vimentin + cells matches the increase in laminin.

\section{The subventricular zone and ependyma mimic the lesion environment}

An area of the brain in which serotonergic neurons naturally are present at far higher density than other types of neurons is in the subventricular zone and ependyma surrounding the lateral ventricles (Lorez and Richards, 1982) (Fig. 5). Both 5-HT (Fig. 5a,e) and SERT (Fig. 5b,f) label the high-density serotonergic fibers along the lateral ventricle. Similar to the lesion, both vimentin+ (Figs. $5 c, g, 6 a, c)$ and GFAP $+($ Fig. $6 b, c)$ cells are present in the subventricular zone (SVZ). Vimentin + cells form the innermost ependymal layer, followed by GFAP + cells more peripherally and extending toward and along the corpus callosum. This pattern mirrors that in the cortical lesion except that there is no region of GFAP+/vimentin+ colabeling. Laminin immunostaining occurs in the same location as the vimentin + cells, is punctate and extravascular (Fig. $6 d$ ), and does not match blood vessel staining (Fig. $6 f$ ). These finely networked laminin structures called fractones are, instead, anchored to blood vessels (Mercier et al., 2002). CSPG is also present, albeit in varying levels, surrounding the entire ventricle (Fig. 6e) in both the GFAP and vimentin compartments. Interestingly, serotonergic fibers are at higher density on the medial (rather than the lateral) wall of the ventricle, where GFAP and CSPG immunostaining is slightly lower than elsewhere. Thus, both the lesion and the ependyma of the lateral ventricle contain laminin, vimentin, CSPG and GFAP. This combination may form a unique niche that enhances serotonergic fiber sprouting.

\section{Serotonergic growth cones remain more active than cortical growth cones when challenged with CSPG in vitro}

To investigate the mechanisms that serotonergic neurons use to persist in the lesion and resist dieback, the response of serotonergic and cortical fibers to substrates of high levels of CSPG and low levels of laminin was studied in vitro. We used P3-P4 ePet-EYFP transgenic mice whose serotonergic neurons are labeled by EYFP under control of the Pet-1 enhancer/promoter region. This serotonin neuron-specific transcription factor begins expression early in development and continues throughout adulthood (Hendricks et al., 1999; Scott et al., 2005a,b; Hawthorne et al., 2010). It was not feasible to harvest sufficient quantities of 5-HT neurons from older animals. EYFP-negative littermates were used for the cortical cultures. Neurons were grown on uniform substrates of PLL or PLL plus $1 \mu \mathrm{g} / \mathrm{ml}$ laminin with or without $100 \mu \mathrm{g} / \mathrm{ml}$ aggrecan for $2 \mathrm{DIV}$, at which time their growth cones were imaged by time-lapse microscopy every $30 \mathrm{~s}$ for $1-2 \mathrm{~h}$. Serotonergic neurons were identified by endogenous EYFP fluorescence before starting time-lapse imaging in phase contrast. 

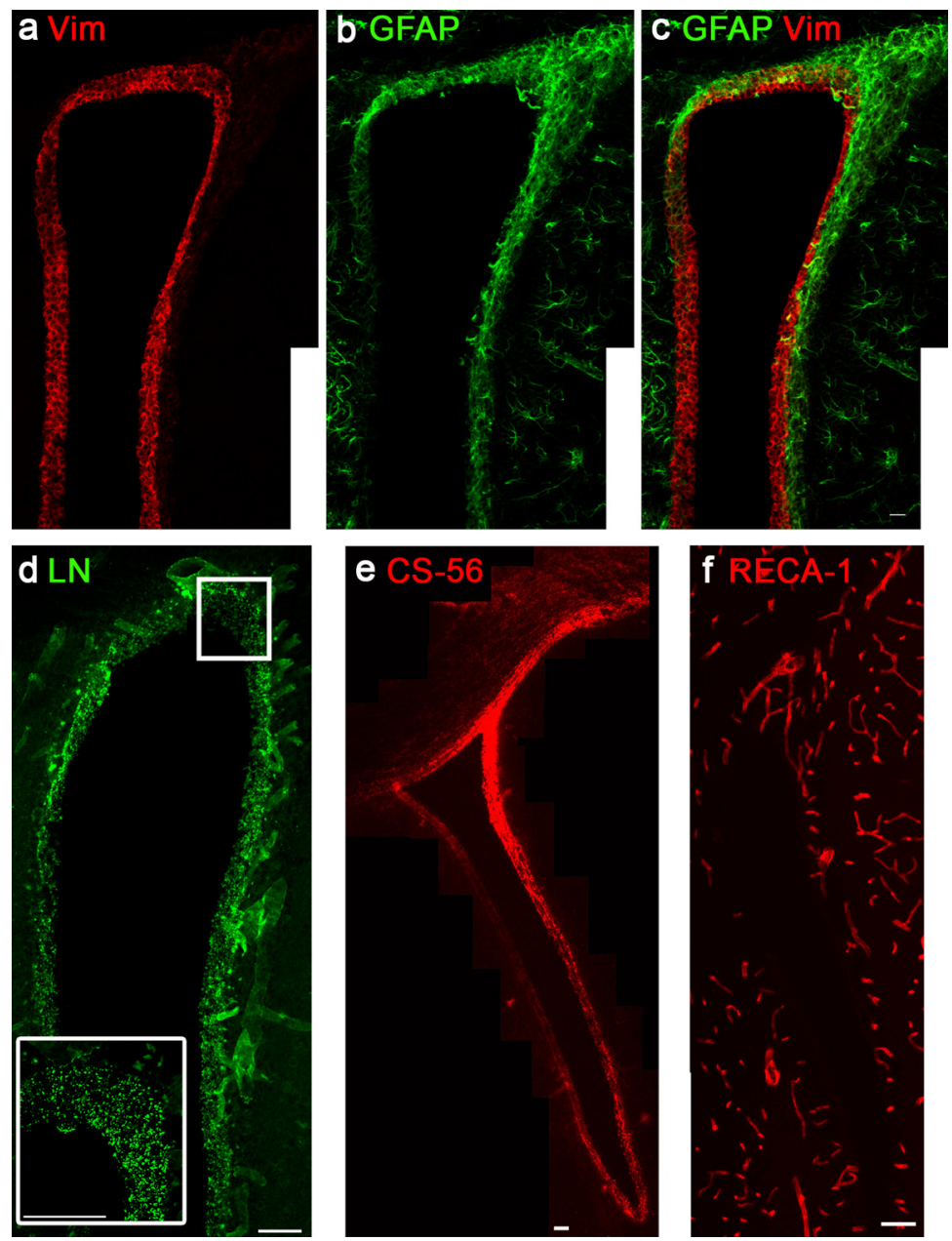

Figure 6. The ventricular zone and ependyma mirror the lesion environment. $\boldsymbol{a}-\boldsymbol{c}$, Vimentin + cells line the lateral ventricle ependyma $(\boldsymbol{a}, \boldsymbol{c})$, then GFAP + cells extend into the tissue $(\boldsymbol{b}, \boldsymbol{c}) \cdot \boldsymbol{d}$, Laminin $(\mathrm{LN})$ immunostaining is present in the same area as vimentin + cells, both punctate (inset) and around large blood vessels. e, CSPG labeled by CS-56 is in the same location as GFAP + cells, lining the lateral ventricles and extending into the corpus callosum. $f$, Large blood vessels labeled by RECA-1 do not contribute all of the laminin. Images are from an uninjured lateral ventricle. Scale bars: $\boldsymbol{a}-\boldsymbol{c}, 20 \mu \mathrm{m} ; \boldsymbol{d}-\boldsymbol{f}, 50 \mu \mathrm{m}$.

Growth cones had minimal activity on PLL alone (Movie 1; see Notes). On laminin, both cortical and serotonergic (Movie 2; see Notes) growth cones were mostly active and progressed forward. Both types of neurons typically possessed growth cones that extended dynamic filopodia and lamellipodia (Movie 2; see Notes). Some neurons at the time of imaging displayed an active growth cone but no forward progress.

When the substrate contained the inhibitory CSPG aggrecan as well as laminin, the behavior of both types of growth cones was altered; however, serotonergic growth cones remained much more active. Most cortical growth cones became straight and formed simple, pencil-shaped endings that lacked activity (Movie 3a; see Notes). These processes without any observable forward growth differed drastically from the dynamic growth cones on laminin alone. Occasionally, cortical growth cones on CSPG were active but typically lacked forward progress. Serotonergic growth cones on aggrecan/laminin more closely resembled their counterparts on laminin alone (Movie 3b; see Notes). Serotonergic growth cones were mostly active with fast-moving filopodia, and in fortuitous cultures could be compared with the dystrophic EYFP-negative growth cone in the same field of view (Movie 3b; see Notes). Although highly active on CSPG, serotonergic neuronal growth cones often lacked forward growth and instead usually remained in place. A few did achieve forward growth, while others were inactive but stable, i.e., not moving forward or retracting. The behavior of growth cones of both types of neuron on all substrates was quantified into three classes: forward progression of the growth cone, activity at the growth cone without forward progression, and an inactive growth cone that was stable and not retracting (Fig. 7a). Serotonergic neurons had less of a shift toward inactive behavior than cortical neurons. Overall, serotonergic neurons maintained a more robust growth cone when grown on the challenging substrate of high levels of aggrecan plus low levels of laminin, whereas cortical neurons mostly lacked growth cones and lost their dynamic ability.

\section{ChABC treatment relieves CSPG inhibition in vitro}

The time-lapse movies (see Notes) revealed that, while serotonergic neurons were able to maintain a more active growth cone in a high-CSPG environment than cortical neurons, serotonergic growth cones usually did not make forward progress. To test whether the neurons could resume forward growth after developing this stalled state, the inhibitory glycosaminoglycan (GAG) chains were cleaved from aggrecan using the bacterial enzyme ChABC. Neurons were grown on a mixed substrate of $100 \mu \mathrm{g} / \mathrm{ml}$ aggrecan and $1 \mu \mathrm{g} / \mathrm{ml}$ laminin for $1 \mathrm{DIV}$. Then, medium was replaced with that containing $0.5 \mathrm{U}$ of ChABC or saline to each culture dish. One day later, for 2 DIV total, cells were fixed, and neurite lengths were compared. Both types of neurons exhibited increased growth with ChABC treatment, although the growth was only significant for serotonergic fibers (Fig. $7 b-f$; Kruskal-Wallis test, $\chi^{2}(3)=$ 48.422, post hoc Mann-Whitney $U$ test, serotonergic $U=234.00$, $p<0.001$; cortical $U=10,108, p=0.06$ ). There likely was not as large of an increase in cortical neurons after ChABC treatment because the growth cones were in a less active state than serotonergic growth cones and there are very low levels of laminin present to support robust growth. Serotonergic fibers treated with $\mathrm{ChABC}$ were also significantly longer than cortical neurons treated with saline $(U=1616, p<0.001)$ or ChABC $(U=2198$, $p<0.001)$. Therefore, serotonergic neurons were able to increase the forward movement of their growth cones after relieving CSPG inhibition on minimal amounts of laminin, which is an enhanced response to $\mathrm{ChABC}$ treatment compared with cortical neurons.

\section{Serotonergic neurons express higher levels of GAP-43 and $\beta 1$} integrin than do cortical neurons

Both the increased activity of the growth cone on aggrecan plus low laminin and the increased ability to respond to ChABC treatment indicate that serotonergic neurons possess cell-intrinsic properties that allow them to maintain a more active growth state 
than cortical neurons. This is reflected in the lesion environment as well, where serotonergic fibers persist and sprout, while cortical fibers die back. So, we investigated the potential molecular mechanisms by which serotonergic neurons maintain active growth cones despite inhibitory extracellular substrates. GAP-43 is associated with developing and regenerating axons (Skene and Willard, 1981; Jacobson et al., 1986) and is required postnatally for serotonergic terminal arborization (Donovan et al., 2002). GAP-43 mRNA has been found in serotonergic cell bodies in adulthood (Bendotti et al., 1991). So, we hypothesized that serotonergic neurons would have higher expression of GAP-43 than cortical neurons. Both cortical and serotonergic neurons expressed GAP-43 in vitro on both laminin (Fig. $8 a-d$ ) and aggrecan plus laminin (data not shown) substrates. The fluorescence intensity of GAP-43 immunostaining per unit area was quantified in neuronal cell bodies growing on laminin. Indeed, serotonergic neurons expressed significantly higher levels of GAP-43 than cortical neurons [5-HT+, $2054.55 \pm 49.22$ (mean $\pm \mathrm{SEM}$ ) fluorescence intensity/ $\mu \mathrm{m}^{2}$, $n=270$; cortical, $1370.66 \pm 36.31$ fluorescence intensity/ $\mu \mathrm{m}^{2}, n=615$; MannWhitney $U$ test, $U=47,505.00, p<0.001$ ].

Since serotonergic and cortical neurons were differentially affected by a change in extracellular substrate, we hypothesized that serotonergic neurons also had a different receptor repertoire than cortical neurons that allowed serotonergic neurons to maintain a more active growth state despite inhibitory conditions. We immunostained for components of integrin receptors for laminin: $\beta 1, \alpha 1, \alpha 2, \alpha 3$, and $\alpha 6$ integrins (Milner and Campbell, 2002). $\beta 1$ integrin, which forms the basis for all laminin receptor integrin pairs, was expressed at significantly higher levels per unit area in serotonergic neuronal cell bodies than in cortical neuronal cell bodies (Fig. $8 e-h ; 5-\mathrm{HT}+$, $756.58 \pm 21.51$ fluorescence intensity $/ \mu \mathrm{m}^{2}, n=341$; cortical, $225.49 \pm 2.94$ fluorescence intensity/ $\mu \mathrm{m}^{2}, n=462$; MannWhitney $U$ test, $U=3581.00, p<0.001)$. We did not notice any qualitative difference in the expression of $\beta 1$ integrin if neurons were grown on laminin or laminin plus proteoglycan. Since cortical neurons grew so much better without CSPG, we quantified $\beta 1$ integrin expression on the substrate of laminin. Both serotonergic and cortical neurons express appropriate subsets of $\alpha$ integrin subunits that could pair with $\beta 1$ integrin to form receptors for laminin (data not shown). To test whether $\beta 1$ integrin was necessary for serotonergic and cortical neurite outgrowth, neurons were grown on low laminin in the presence of functionblocking anti- $\beta 1$ integrin or isotype control antibody for 1 DIV. The longest neurite was measured for each neuron. Serotonergic neurons achieved significantly longer neurites on low laminin than did cortical neurons (Fig. 8i,k,m; Kruskal-Wallis test, Mann-Whitney $U$ test post hoc, $U=5905.0, p<0.001$ ), and both
$5-\mathrm{HT}+$ and cortical neurons were significantly inhibited by the anti- $\beta 1$ integrin antibody treatment (Fig. $8 i-m$; Kruskal-Wallis test, Mann-Whitney $U$ test post hoc, $U=9277.5$ (5-HT+), 7986.0 (cortical), $p<0.001$ ). Thus, serotonergic and cortical neurons need $\beta 1$ integrin to successfully grow on low levels of laminin. Note that neither serotonergic nor cortical growth cones made any forward progress on a laminin-devoid PLL only environment (Fig. 7a; Movie 1; see Notes). Higher $\beta 1$ integrin subunit expression in serotonergic neurons could partially explain the enhanced ability to respond to low levels of laminin, as seen in vitro and in the lesion environment in vivo.

\section{Discussion}

Serotonergic fibers tend to naturally sprout after injury (Sharma et al., 1990; Zhou et al., 1995; Inman and Steward, 2003; Camand et al., 2004), but the mechanism by which they sprout has not been investigated. Here, we used in vitro modeling of an in vivo lesion to show that $\beta 1$ integrin binding to laminin is critical for serotonergic neurite outgrowth. We show for the first time in a cortical ischemic lesion that serotonergic fibers not only persist at the lesion edge and sprout but appear to be resistant to the forces 

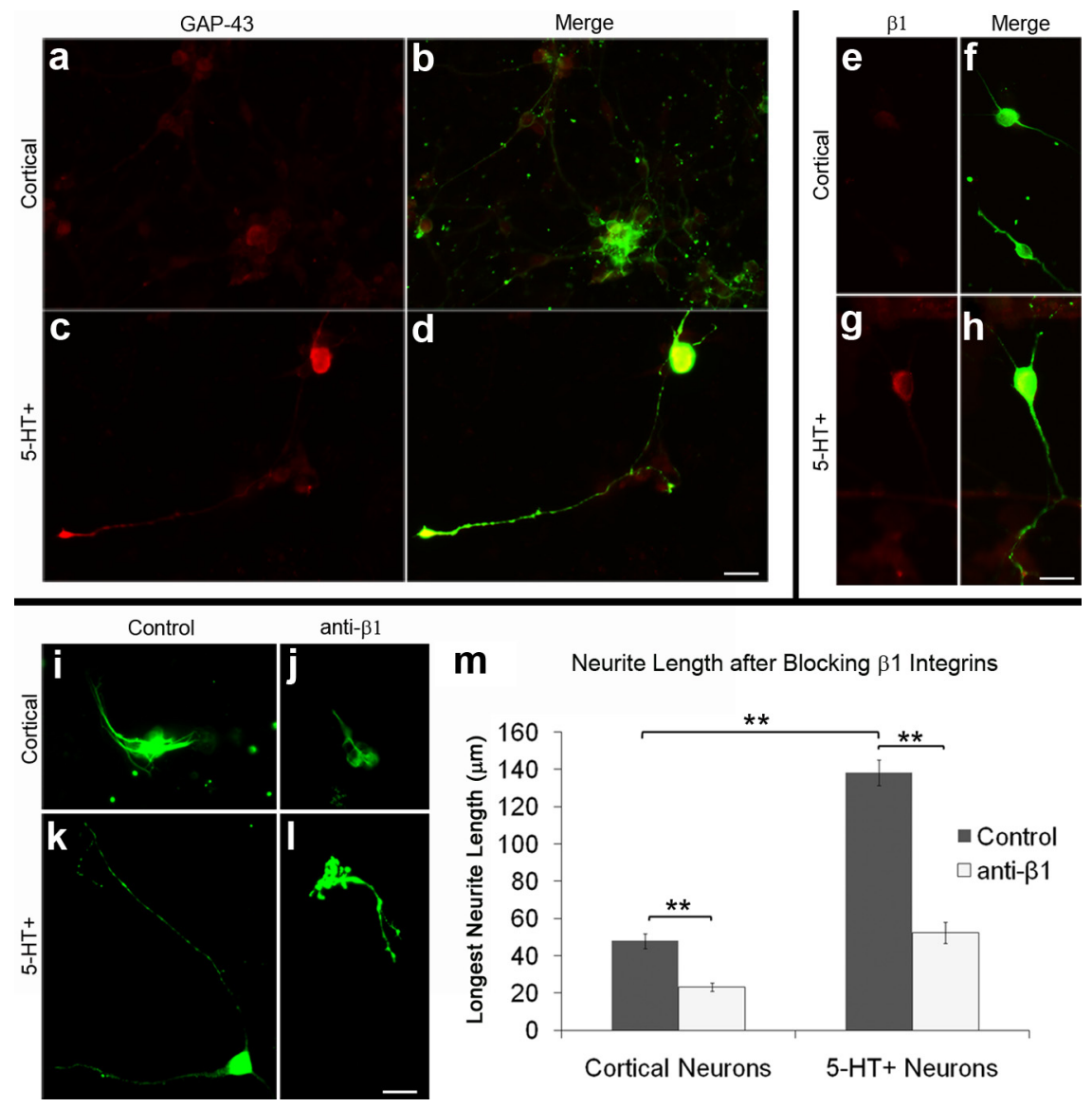

m

Neurite Length after Blocking $\beta 1$ Integrins

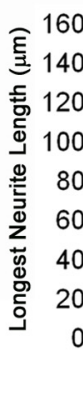

160
140
120
100
80
60
40
20
0

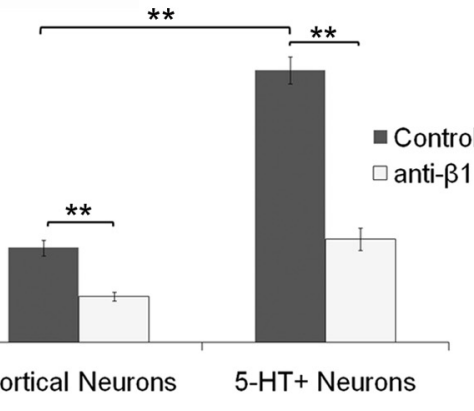

Figure 8. $\quad \boldsymbol{a}-\boldsymbol{d}$, Serotonergic neurons express higher levels of GAP-43. GAP-43(red) is expressed at higher levels in 5-HT+ (green) neurons $(\boldsymbol{c}, \boldsymbol{d})$ than in $\beta$-tubulin III + (green) cortical neurons $(\boldsymbol{a}, \boldsymbol{b}) . \boldsymbol{e}-\boldsymbol{m}$, Serotonergic neurons have higher levels of $\beta 1$ integrin, and growth is blocked with a $\beta 1$ inhibitor. $\beta 1$ integrin (red) is expressed in low levels in $\beta$-tubulin III + cortical cell bodies $(\boldsymbol{e}, \boldsymbol{f}$; green) and in higher levels in 5 -HT + neurons ( $\boldsymbol{g}, \boldsymbol{h}$; green). Anti- $\beta$ 1 integrin $(\boldsymbol{j}, \boldsymbol{I})$ or isotype control $(\boldsymbol{i}, \boldsymbol{k})$ antibody was applied at the time of plating on $1 \mu \mathrm{g} / \mathrm{ml}$ laminin, and the longest neurite was measured after 1 DIV. $\boldsymbol{m}, 0 \mathrm{n}$ laminin, serotonergic neurons grew significantly longer than cortical neurons (Kruskal-Wallis test, Mann-Whitney $U$ test post hoc, $U=5905.0$ ). Compared with isotype control, both 5 -HT + serotonergic $(I)$ and $\beta$-tubulin III + cortical (j) neurite lengths were decreased significantly with the $\beta 1$ function-blocking antibody [Kruskal-Wallis test, Mann-Whitney $U$ test post hoc, $U=9277.5,5-\mathrm{HT}, n=211$ (control), 209 $(\beta 1)$; and $U=7986.0$, cortical, $n=147$ (control), $168(\beta 1)$ ]. Mean \pm SEM is displayed. Scale bar, $20 \mu \mathrm{m} .{ }^{* *} p<0.001$.

that cause axonal dieback. Sprouting at 3 weeks after lesion agrees with previous research that showed sprouted serotonergic fibers in the hippocampus after 2 weeks and as long as one year (Azmitia et al., 1978; Zhou and Azmitia, 1984; Azmitia, 1986; Azmitia and Whitaker-Azmitia, 1991). Our in vitro studies using time-lapse imaging have demonstrated that serotonergic growth cones are more active than cortical growth cones when challenged with CSPG, and serotonergic neurons can better recover after enzymatic digestion with $\mathrm{ChABC}$, indicating that serotonergic fibers may be more responsive to treatment in vivo as well. This could be due, at least in part, to cytoskeletal or receptor differences. The robust behavior of serotonergic neurons may be linked to their increased expression of GAP-43, which is associated with the growth or regeneration of axons and is usually downregulated in adulthood (Skene and Willard, 1981; Jacobson et al., 1986). Overexpression of GAP-43 results in increased axonal sprouting, both pre-injury and post-injury (Aigner et al., 1995). Serotonergic neurons require GAP-43 postnatally for proper terminal arborization in the forebrain (Donovan et al., 2002). Additionally, adult serotonergic neurons continue to make GAP-43 mRNA (Bendotti et al., 1991), which may prime 5-HT fibers to respond better to injury.
Serotonergic growth cones have fastmoving, dynamic filopodia, even when challenged with inhibitory CSPG, indicating rapid F-actin turnover (Gallo and Letourneau, 2004). Filopodia allow for sampling the environment and for the formation of axonal branches (Gallo and Letourneau, 2004). Most cortical neurites grown on aggrecan plus laminin lack filopodia or lamellipodia, indicating growth cone collapse. The morphology of postnatal serotonergic growth cones resembles embryonic dorsal root ganglion (DRG) growth cones, which are more resistant to the negative effects of CSPG than adult dorsal root ganglia (DRGs) (Busch et al., 2009). Even embryonically, serotonergic neurons exhibit more growth potential on CSPG than cortical neurons, which highly fasciculate to avoid contact with the substrate (data not shown). During development and into adulthood, serotonergic fibers grow in the SVZ, a region largely devoid of other axons. So, serotonergic neurons may grow better in inhibitory environments than other neurons throughout life.

A conditioning lesion, whereby the peripheral axon of a sensory neuron is cut or crushed, results in increased growth after subsequent injury to the CNS branch of the same neuron (McQuarrie and Grafstein, 1973; Neumann and Woolf, 1999). A number of factors are up- or downregulated after conditioning. For instance, GAP-43 is upregulated in conditioned DRGs (Van der Zee et al., 1989; Chong et al., 1994; Ylera et al., 2009). Sciatic nerve transection results in increased $\alpha 6, \alpha 7$, and $\beta 1$ integrin subunit expression, which can form receptors for laminin (Hammarberg et al., 2000). Indeed, conditioning allows neurons to increase their responsiveness to laminin (Werner et al., 2000; Ekström et al., 2003). Blocking $\beta 1$ integrin in vitro abrogates this response (Werner et al., 2000; Ekström et al., 2003). Based on the increased expression of GAP-43 and $\beta 1$ integrin, growth inhibition by blocking $\beta 1$ integrin, the morphology of the growth cone in vitro, and the increased growth response in vivo, serotonergic neurons behave as if they might be intrinsically conditioned. Thus, upon injury, serotonergic fibers are able to survive and sprout better than most other neuronal subtypes. The natural enhanced growth capacity coupled with the ability to use even small amounts of laminin in an inhibitory environment likely mediated the successful growth of serotonergic fibers after axotomy.

Another type of neuron that has enhanced growth abilities after lesion is the commissural interneuron in the adult cat spinal cord (Fenrich et al., 2007; Fenrich and Rose, 2009). After a midline microlesion, the axotomized interneurons demonstrated the remarkable ability to regrow axons from both axons and dendrites. These de novo axons pass the lesion and cross the midline, forming functional connections (Fenrich et al., 2007; Fenrich and Rose, 2009). Some of these processes expressed GAP-43 (Fenrich et al., 2007). The impetus for sprouting and exuberant growth in 
the spinal cord is unclear, but certainly a more detailed comparison of the commissural interneurons with serotonergic neurons would shed light on the regeneration and sprouting processes.

Serotonergic growth cones may also be stabilized by enhanced $\beta 1$ integrin expression. Integrins signal via the MAPK pathway to influence cell survival and growth cone motility through the actin cytoskeleton (Giancotti and Ruoslahti, 1999). Neuronal integrin receptors for laminin include the $\beta 1$ subunit paired with an $\alpha$ subunit, including $\alpha 1, \alpha 2, \alpha 3, \alpha 6$, and $\alpha 7$ (Milner and Campbell, 2002; Ekström et al., 2003). Both serotonergic and cortical neurons expressed appropriate subunits to form laminin receptors, but serotonergic neurons expressed significantly higher levels of the $\beta 1$ subunit, indicating the potential to form a higher number of receptors for laminin. Integrin receptors were upregulated on the surfaces of immature DRG neurons successfully growing on CSPGs, but adult sensory neurons did not have the same response (Condic et al., 1999; Condic, 2001; Lemons et al., 2005; Lemons and Condic, 2008). The outgrowth of adult DRGs on laminin alone and proteoglycan plus laminin was greatly enhanced by adenoviral addition of the $\alpha 1$ integrin subunit, suggesting that the upregulation of integrins may be enough to enhance the growth of adult neurons after lesion in vivo (Condic, 2001; Lemons and Condic, 2008). Therefore, serotonergic neurons seem to be better equipped to respond to the laminin in the lesion environment, even if it may be relatively sparse, which may allow the fibers to sprout despite the high levels of CSPG.

Activated macrophages/microglia in lesions may be harmful to dystrophic but not healthy or conditioned axons (Horn et al., 2008; Busch et al., 2009; Gensel et al., 2009; Kigerl et al., 2009). $\mathrm{BDA}+$ fibers were dystrophic in the lesion, whereas serotonergic fibers were not. Since macrophages/microglia were positive for $\mathrm{BDA}$ and engulfed BDA+ fibers, macrophages/microglia may contribute to the retraction of dystrophic cortical processes toward the corpus callosum and away from the higher concentrations of macrophages/microglia located more dorsally. Serotonergic fibers may survive among the macrophages/microglia without negative consequence because they are not dystrophic and maintain a healthier growth state.

Laminin upregulation in the lesion corresponds to the same region and time course as vimentin immunostaining. These vimentin + cells may be astrocytes (Bernstein et al., 1985), fibroblasts (Sievers et al., 1994), or endothelial cells (Gospodarowicz et al., 1981), all of which can secrete laminin. NG2 + cells can express laminin (Yang et al., 2006) and vimentin (Horky et al., 2006; Busch et al., 2010) and may be beneficial to neuronal growth (Yang et al., 2006; Busch et al., 2010). While NG2 + cells increase in spinal cord injury models (McTigue et al., 2001; McTigue et al., 2006), we have not found substantial NG2 staining in this model beyond the transient increase that occurs early after injury (data not shown). This may be because the damage is confined to the cortex and does not spread to the myelin-containing corpus callosum. Thus, the precise identity of the cells that secrete laminin is not yet known, but laminin appears to be the substrate upon which 5-HT axons navigate within the lesion environment.

Recently, transmembrane protein tyrosine phosphatase $\sigma$ $(\mathrm{PTP} \sigma)$ was identified as the first known receptor that mediates the repulsive properties of CSPGs (Shen et al., 2009). Another possibility that could contribute to the enhanced growth abilities of serotonergic neurons in the lesion is that they may have a decreased number of CSPG receptors, allowing serotonergic neurons to better tolerate the inhibitory CSPG-filled lesion environment. Serotonergic neurite outgrowth is negatively affected by CSPG, so it is unlikely that they would lack all CSPG receptors.
There are likely other receptors in the leukocyte antigen-related (LAR) family to CSPGs (Shen et al., 2009), and neurons could also be reacting secondarily to the negative charges on CSPGs (Dillon et al., 2000). Unfortunately, there are limited antibodies to PTP $\sigma$, so we were not able to check for expression in serotonergic or cortical neurons. As more reagents become available, this is an important future direction to pursue.

We have taken the initial steps toward answering the important question of why serotonergic neurons are so much better at sprouting than other neuronal subtypes, namely, because they fail to die back, maintain a more active growth cone, have increased GAP-43 and increased $\beta 1$ integrin subunit expression, upon which they are dependent for growth in a restricted laminin-containing environment. No doubt there are other defining qualities that contribute to the robust response of serotonergic neurons to injury. Discovering why serotonergic fibers survive in such inhibitory environments could help in the search for therapeutic interventions for both brain and spinal cord injury.

\section{Notes}

Supplemental Movies 1-3 are available at http://filer.case.edu/jxs10/5HT_Movies/.

\section{References}

Aigner L, Arber S, Kapfhammer JP, Laux T, Schneider C, Botteri F, Brenner HR, Caroni P (1995) Overexpression of the neural growth-associated protein GAP-43 induces nerve sprouting in the adult nervous system of transgenic mice. Cell 83:269-278.

Akers RM, Killackey HP (1978) Organization of corticocortical connections in the parietal cortex of the rat. J Comp Neurol 181:513-537.

Azmitia EC (1986) Reengineering the brain serotonin system: localized application of specific neurotoxins and fetal serotonergic neurons into the adult CNS. Adv Neurol 43:493-507.

Azmitia EC, Whitaker-Azmitia PM (1991) Awakening the sleeping giant: anatomy and plasticity of the brain serotonergic system. J Clin Psychiatry 52 [Suppl]:4-16.

Azmitia EC, Buchan AM, Williams JH (1978) Structural and functional restoration by collateral sprouting of hippocampal 5-HT axons. Nature 274:374-376.

Bendotti C, Servadio A, Samanin R (1991) Distribution of GAP-43 mRNA in the brain stem of adult rats as evidenced by in situ hybridization: localization within monoaminergic neurons. J Neurosci 11:600-607.

Bernstein JJ, Getz R, Jefferson M, Kelemen M (1985) Astrocytes secrete basal lamina after hemisection of rat spinal cord. Brain Res 327:135-141.

Brewer GJ, Torricelli JR (2007) Isolation and culture of adult neurons and neurospheres. Nat Protoc 2:1490-1498.

Busch SA, Silver J (2007) The role of extracellular matrix in CNS regeneration. Curr Opin Neurobiol 17:120-127.

Busch SA, Horn KP, Silver DJ, Silver J (2009) Overcoming macrophagemediated axonal dieback following CNS injury. J Neurosci 29:9967-9976.

Busch SA, Horn KP, Cuascut FX, Hawthorne AL, Bai L, Miller RH, Silver J (2010) Adult NG2 + cells are permissive to neurite outgrowth and stabilize sensory axons during macrophage-induced axonal dieback after spinal cord injury. J Neurosci 30:255-265.

Camand E, Morel MP, Faissner A, Sotelo C, Dusart I (2004) Long-term changes in the molecular composition of the glial scar and progressive increase of serotoninergic fibre sprouting after hemisection of the mouse spinal cord. Eur J Neurosci 20:1161-1176.

Chong MS, Reynolds ML, Irwin N, Coggeshall RE, Emson PC, Benowitz LI, Woolf CJ (1994) GAP-43 expression in primary sensory neurons following central axotomy. J Neurosci 14:4375-4384.

Condic ML (2001) Adult neuronal regeneration induced by transgenic integrin expression. J Neurosci 21:4782-4788.

Condic ML, Snow DM, Letourneau PC (1999) Embryonic neurons adapt to the inhibitory proteoglycan aggrecan by increasing integrin expression. J Neurosci 19:10036-10043.

Correia I, Chu D, Chou YH, Goldman RD, Matsudaira P (1999) Integrating 
the actin and vimentin cytoskeletons. adhesion-dependent formation of fimbrin-vimentin complexes in macrophages. J Cell Biol 146:831-842.

Dillon GP, Yu X, Bellamkonda RV (2000) The polarity and magnitude of ambient charge influences three-dimensional neurite extension from DRGs. J Biomed Mater Res 51:510-519.

Donovan SL, Mamounas LA, Andrews AM, Blue ME, McCasland JS (2002) GAP-43 is critical for normal development of the serotonergic innervation in forebrain. J Neurosci 22:3543-3552.

Ekström PA, Mayer U, Panjwani A, Pountney D, Pizzey J, Tonge DA (2003) Involvement of alpha7betal integrin in the conditioning-lesion effect on sensory axon regeneration. Mol Cell Neurosci 22:383-395.

Fenrich KK, Rose PK (2009) Spinal interneuron axons spontaneously regenerate after spinal cord injury in the adult feline. J Neurosci 29: $12145-12158$.

Fenrich KK, Skelton N, MacDermid VE, Meehan CF, Armstrong S, NeuberHess MS, Rose PK (2007) Axonal regeneration and development of de novo axons from distal dendrites of adult feline commissural interneurons after a proximal axotomy. J Comp Neurol 502:1079-1097.

Feraboli-Lohnherr D, Orsal D, Yakovleff A, Giménez y Ribotta M, Privat A (1997) Recovery of locomotor activity in the adult chronic spinal rat after sublesional transplantation of embryonic nervous cells: specific role of serotonergic neurons. Exp Brain Res 113:443-454.

Fitch MT, Silver J (2008) CNS injury, glial scars, and inflammation: inhibitory extracellular matrices and regeneration failure. Exp Neurol 209:294-301.

Foster GA, Roberts MH, Wilkinson LS, Björklund A, Gage FH, Hökfelt T, Schultzberg M, Sharp T (1989) Structural and functional analysis of raphe neurone implants into denervated rat spinal cord. Brain Res Bull 22:131-137.

Fujimoto T, Singer SJ (1986) Immunocytochemical studies of endothelial cells in vivo. I. The presence of desmin only, or of desmin plus vimentin, or vimentin only, in the endothelial cells of different capillaries of the adult chicken. J Cell Biol 103:2775-2786.

Gallo G, Letourneau PC (2004) Regulation of growth cone actin filaments by guidance cues. J Neurobiol 58:92-102.

Gensel JC, Nakamura S, Guan Z, van Rooijen N, Ankeny DP, Popovich PG (2009) Macrophages promote axon regeneration with concurrent neurotoxicity. J Neurosci 29:3956-3968.

Giancotti FG, Ruoslahti E (1999) Integrin signaling. Science 285:1028-1032.

Gospodarowicz D, Greenburg G, Foidart JM, Savion N (1981) The production and localization of laminin in cultured vascular and corneal endothelial cells. J Cell Physiol 107:171-183.

Hammarberg H, Wallquist W, Piehl F, Risling M, Cullheim S (2000) Regulation of laminin-associated integrin subunit mRNAs in rat spinal motoneurons during postnatal development and after axonal injury. J Comp Neurol 428:294-304.

Hawthorne AL, Wylie CJ, Landmesser LT, Deneris ES, Silver J (2010) Serotonergic neurons migrate radially through the neuroepithelium by dynamin-mediated somal translocation. J Neurosci 30:420-430.

Hendricks T, Francis N, Fyodorov D, Deneris ES (1999) The ETS domain factor Pet-1 is an early and precise marker of central serotonin neurons and interacts with a conserved element in serotonergic genes. J Neurosci 19:10348-10356.

Holwell TA, Schweitzer SC, Evans RM (1997) Tetracycline regulated expression of vimentin in fibroblasts derived from vimentin null mice. J Cell Sci 110:1947-1956.

Horky LL, Galimi F, Gage FH, Horner PJ (2006) Fate of endogenous stem/ progenitor cells following spinal cord injury. J Comp Neurol 498:525-538.

Horn KP, Busch SA, Hawthorne AL, van Rooijen N, Silver J (2008) Another barrier to regeneration in the CNS: activated macrophages induce extensive retraction of dystrophic axons through direct physical interactions. J Neurosci 28:9330-9341.

Inman DM, Steward O (2003) Ascending sensory, but not other long-tract axons, regenerate into the connective tissue matrix that forms at the site of a spinal cord injury in mice. J Comp Neurol 462:431-449.

Jacobson RD, Virág I, Skene JH (1986) A protein associated with axon growth, GAP-43, is widely distributed and developmentally regulated in rat CNS. J Neurosci 6:1843-1855.

Kigerl KA, Gensel JC, Ankeny DP, Alexander JK, Donnelly DJ, Popovich PG (2009) Identification of two distinct macrophage subsets with divergent effects causing either neurotoxicity or regeneration in the injured mouse spinal cord. J Neurosci 29:13435-13444.

Koralek KA, Olavarria J, Killackey HP (1990) Areal and laminar organization of corticocortical projections in the rat somatosensory cortex. J Comp Neurol 299:133-150.

Lemons ML, Condic ML (2008) Integrin signaling is integral to regeneration. Exp Neurol 209:343-352.

Lemons ML, Barua S, Abanto ML, Halfter W, Condic ML (2005) Adaptation of sensory neurons to hyalectin and decorin proteoglycans. J Neurosci 25:4964-4973.

Levitt P, Moore RY (1978) Developmental organization of raphe serotonin neuron groups in the rat. Anat Embryol (Berl) 154:241-251.

Lorez HP, Richards JG (1982) Supra-ependymal serotoninergic nerves in mammalian brain: morphological, pharmacological and functional studies. Brain Res Bull 9:727-741.

McQuarrie IG, Grafstein B (1973) Axon outgrowth enhanced by a previous nerve injury. Arch Neurol 29:53-55.

McTigue DM, Wei P, Stokes BT (2001) Proliferation of NG2-positive cells and altered oligodendrocyte numbers in the contused rat spinal cord. J Neurosci 21:3392-3400.

McTigue DM, Tripathi R, Wei P (2006) NG2 colocalizes with axons and is expressed by a mixed cell population in spinal cord lesions. J Neuropathol Exp Neurol 65:406-420.

Mercier F, Kitasako JT, Hatton GI (2002) Anatomy of the brain neurogenic zones revisited: fractones and the fibroblast/macrophage network. J Comp Neurol 451:170-188.

Milner R, Campbell IL (2002) The integrin family of cell adhesion molecules has multiple functions within the CNS. J Neurosci Res 69:286-291.

Neumann S, Woolf CJ (1999) Regeneration of dorsal column fibers into and beyond the lesion site following adult spinal cord injury. Neuron 23:83-91.

Nicolelis MA, Chapin JK, Lin CS (1991) Ontogeny of corticocortical projections of the rat somatosensory cortex. Somatosens Mot Res 8:193-200.

Privat A, Mansour H, Pavy A, Geffard M, Sandillon F (1986) Transplantation of dissociated foetal serotonin neurons into the transected spinal cord of adult rats. Neurosci Lett 66:61-66.

Ramon y Cajal S (1928) Degeneration and regeneration of the nervous system. London: Oxford UP.

Ribotta MG, Provencher J, Feraboli-Lohnherr D, Rossignol S, Privat A, Orsal D (2000) Activation of locomotion in adult chronic spinal rats is achieved by transplantation of embryonic raphe cells reinnervating a precise lumbar level. J Neurosci 20:5144-5152.

Schachtrup C, Lu P, Jones LL, Lee JK, Lu J, Sachs BD, Zheng B, Akassoglou K (2007) Fibrinogen inhibits neurite outgrowth via beta 3 integrinmediated phosphorylation of the EGF receptor. Proc Natl Acad Sci U S A 104:11814-11819.

Scott MM, Krueger KC, Deneris ES (2005a) A differentially autoregulated Pet- 1 enhancer region is a critical target of the transcriptional cascade that governs serotonin neuron development. J Neurosci 25:2628-2636.

Scott MM, Wylie CJ, Lerch JK, Murphy R, Lobur K, Herlitze S, Jiang W, Conlon RA, Strowbridge BW, Deneris ES (2005b) A genetic approach to access serotonin neurons for in vivo and in vitro studies. Proc Natl Acad Sci U S A 102:16472-16477.

Sharma HS, Westman J, Olsson Y, Johansson O, Dey PK (1990) Increased 5 -hydroxytryptamine immunoreactivity in traumatized spinal cord. An experimental study in the rat. Acta Neuropathol 80:12-17.

Shen Y, Tenney AP, Busch SA, Horn KP, Cuascut FX, Liu K, He Z, Silver J, Flanagan JG (2009) PTPsigma is a receptor for chondroitin sulfate proteoglycan, an inhibitor of neural regeneration. Science 326:592-596.

Sievers J, Pehlemann FW, Gude S, Berry M (1994) Meningeal cells organize the superficial glia limitans of the cerebellum and produce components of both the interstitial matrix and the basement membrane. J Neurocytol 23:135-149.

Silver J, Miller JH (2004) Regeneration beyond the glial scar. Nat Rev Neurosci 5:146-156.

Skene JH, Willard M (1981) Characteristics of growth-associated polypeptides in regenerating toad retinal ganglion cell axons. J Neurosci 1:419-426.

Szele FG, Alexander C, Chesselet MF (1995) Expression of molecules associated with neuronal plasticity in the striatum after aspiration and thermocoagulatory lesions of the cerebral cortex in adult rats. J Neurosci 15:4429-4448.

Tom VJ, Steinmetz MP, Miller JH, Doller CM, Silver J (2004) Studies on the development and behavior of the dystrophic growth cone, the hallmark of 
regeneration failure, in an in vitro model of the glial scar and after spinal cord injury. J Neurosci 24:6531-6539.

Van der Zee CE, Nielander HB, Vos JP, Lopes da Silva S, Verhaagen J, Oestreicher AB, Schrama LH, Schotman P, Gispen WH (1989) Expression of growth-associated protein B-50 (GAP43) in dorsal root ganglia and sciatic nerve during regenerative sprouting. J Neurosci 9:3505-3512.

Wallace JA, Lauder JM (1983) Development of the serotonergic system in the rat embryo: an immunocytochemical study. Brain Res Bull 10:459-479.

Werner A, Willem M, Jones LL, Kreutzberg GW, Mayer U, Raivich G (2000) Impaired axonal regeneration in alpha7 integrin-deficient mice. J Neurosci 20:1822-1830.

Yakovleff A, Cabelguen JM, Orsal D, Gimenez y Ribotta M, Rajaofetra N, Drian MJ, Bussel B, Privat A (1995) Fictive motor activities in adult chronic spinal rats transplanted with embryonic brainstem neurons. Exp Brain Res 106:69-78.
Yang HY, Lieska N, Shao D, Kriho V, Pappas GD (1994) Proteins of the intermediate filament cytoskeleton as markers for astrocytes and human astrocytomas. Mol Chem Neuropathol 21:155-176.

Yang Z, Suzuki R, Daniels SB, Brunquell CB, Sala CJ, Nishiyama A (2006) NG2 glial cells provide a favorable substrate for growing axons. J Neurosci 26:3829-3839.

Ylera B, Ertürk A, Hellal F, Nadrigny F, Hurtado A, Tahirovic S, Oudega M, Kirchhoff F, Bradke F (2009) Chronically CNS-injured adult sensory neurons gain regenerative competence upon a lesion of their peripheral axon. Curr Biol 19:930-936.

Zhou FC, Azmitia EC (1984) Induced homotypic collateral sprouting of serotonergic fibers in the hippocampus of rat. Brain Res 308:53-62.

Zhou FC, Azmitia EC, Bledsoe S (1995) Rapid serotonergic fiber sprouting in response to ibotenic acid lesion in the striatum and hippocampus. Brain Res Dev Brain Res 84:89-98. 